\title{
Структурные и морфологические свойства гибридных гетероструктур на основе GaN, выращенного на „податливой“ подложке por-Si(111)
}

\author{
() П.В. Середин ${ }^{1,2}$, Д.Л. Голощапов ${ }^{1}$, Д.С. Золотухин ${ }^{1}$, А.С. Леньшин ${ }^{1}$, А.М. Мизеров ${ }^{3}$, \\ И.Н. Арсентьев ${ }^{4}$, Harald Leiste ${ }^{5}$, Monika Rinke ${ }^{5}$ \\ ${ }^{1}$ Воронежский государственный университет, \\ 394006 Воронеж, Россия \\ 2 Уральский федеральный университет им. первого Президента России Б.Н. Ельцина, \\ 620002 Екатеринбург, Россия \\ ${ }^{3}$ Санкт-Петербургский национальный исследовательский Академический университет Российской академии наук, \\ 194021 Санкт-Петербург, Россия \\ ${ }^{4}$ Физико-технический институт им. А.Ф. Иоффре Российской академии наук, \\ 194021 Санкт-Петербург, Россия \\ ${ }^{5}$ Karlsruhe Nano Micro Facility H.-von-Helmholtz-Platz 1, \\ 76344 Eggenstein-Leopoldshafen, Germany \\ E-mail: paul@phys.vsu.ru; andreymizerov@rambler.ru; arsentyev@mail.ioffe.ru
}

Поступила в Редакцию 12 февраля 2019 г.

В окончательной редакции 1 апреля 2019 г.

Принята к публикации 1 апреля 2019 г.

\begin{abstract}
Показана возможность синтеза интегрированных гетероструктур $\mathrm{GaN} /$ por-Si методом молекулярнопучковой эпитаксии с плазменной активацией азота (МПЭ ПА) без использования буферного слоя AlN/Si. Показано положительное влияние высокотемпературной нитридизации кремниевой подложки, проводимой непосредственно перед ростом GaN, на кристаллическое качество слоев GaN/Si. Установлено, что для получения двумерных слоев $\mathrm{GaN}$ на $\mathrm{Si}(111)$ целесообразно использовать „податливые“ подложки por-Si и низкотемпературные зародышевые слои $\mathrm{GaN}$ с трехмерной (3D) морфологией, которые синтезируются методом МПЭ ПА при относительно низких температурах подложки в стехиометрических условиях при обогащении азотом. В этом случае на поверхности подложки por-Si формируется самоупорядоченный массив зародышевых наноколонн $\mathrm{GaN}$ с достаточно однородным распределением диаметров. В свою очередь, рост основных, слоев GaN следует проводить при повышенной температуре в стехиометрических условиях с обогащением галлием, при которых наблюдается коалесценция зародившихся наноколонн GaN и рост сплошного двумерного слоя $\mathrm{GaN}$. Использование „податливых“ $\mathrm{Si}$-подложек является применимым подходом для формирования полупроводниковых приборных гетероструктур на основе GaN методом МПЭ ПА.
\end{abstract}

Ключевые слова: нитрид галлия, наноколонны, молекулярно-пучковая эпитаксия, пористый кремний, структурные свойства.

DOI: $10.21883 /$ FTP.2019.08.48009.9083

\section{1. Введение}

В последние годы колоссальные исследовательские усилия во всем мире тратятся на изучение различных подходов к интеграции оптических функциональных элементов и кремниевой схемы обработки электрических сигналов. Эта задача диктуется потребностями в развитии и создании нового поколения элементов электронной компонентной базы (datacom и computercom) [1,2], которые требуют гораздо более высокой пропускной способности и меньшей потребляемой мощности по сравнению с существующими сейчас оптоэлектронными элементами. Такую возможность мы можем получить лишь за счет интеграции лазеров и фотодиодов на основе полупроводников групп GaAs и GaN с кремнием в одном гибридном устройстве.

За последние десятилетия было предложено множество подходов для повышения кристаллического качества гетероструктур на основе системы материалов III-N, однако все эти подходы требуют значительного усложнения технологии изготовления приборного слоя, что, естественно, ведет к значительному удорожанию конечной продукции. Решением данной проблемы может быть использование коммерчески доступных „податливых“ Si-подложек, представляющих собой нанопористый слой кремния и сформированную на нем эпитаксиальную структуру с трехмерной (наноколончатой) морфологией.

Ранее нами уже было показано, что использование пористого буферного слоя por-Si при эпитаксиальном росте на кремнии в методах молекулярно-пучковой эпитаксии (MOCVD) и газофазной эпитаксии из металлоорганических соединений (MBE) позволяет снизить величину деформации в эпитаксиальном слое, плотность краевых и винтовых дислокаций по сравнению с величинами аналогичных коэффициентов для слоев, выращенных на $c$-Si, что положительно отражается на кристаллическом качестве эпитаксиального слоя [3-5].

Развиваемый нами подход эпитаксиального выращивания на податливых подложках позволит успешно ин- 
тегрировать химически разнородные материалы с образованием „гибридных“ гетероструктур, объединяющих полупроводниковые соединения группы GaAs и нитридов $\mathrm{A}^{\mathrm{III}} \mathrm{N}$ с кремнием, а самоорганизованный массив нанопор должен позволить получить зародышевые островки $\mathrm{GaN}$ одного диаметра, что в свою очередь приведет к формированию самоупорядоченного массива наноколонн с примерно однородным распределением диаметров.

Поэтому целью данной работы является практическая реализация эпитаксиального выращивания самоупорядоченного массива наноколонн $\mathrm{GaN}$ с их последующей коалесценцией в сплошной двумерный (2D) слой методом молекулярно-пучковой эпитаксии с плазменной активацией азота (МПЭ ПА) на „податливой“ $\mathrm{Si}$-подложке с предварительно сформированным на ней слоем нанопористого кремния por-Si и сопоставление механизмов роста в этом случае и при использовании стандартных подложек $c-\mathrm{Si}$.

\section{2. Материалы и методы исследования}

Эпитаксиальные слои $\mathrm{GaN}$ выращивались методом МПЭ ПА на установке промышленного типа Veeco Gen 200, позволяющей использовать во время одного ростового процесса одновременно до 7 трехдюймовых пластин. Для активации азота использовался высокочастотный (13.56 МГц) плазменный источник Riber RFN 50/63.

Следует отметить, что слои $\mathrm{GaN}$, выращенные на подложках кремния методом МПЭ ПА, имеют, как правило, зеренную (мозаичную) структуру, обусловленную островковым механизмом зарождения $\mathrm{GaN}$ на решеточнорассогласованных подложках кремния. В процессе роста происходит разрастание наноостровков $\mathrm{GaN}$ в наноколонны и их коалесценция в сплошной слой. Вместе с тем известно, что с использованием метода МПЭ ПА возможно формирование как наноколончатых слоев $\mathrm{GaN}$ (в условиях обогащения азотом), так относительно гладких слоев (в условиях обогащения металлом). Кроме того, эффективность активации молекулярного азота при МПЭ ПА не зависит от температуры подложки, что позволяет изменять температуру роста $\mathrm{GaN}$ в широких пределах - от экстремально низких до максимально возможных для данной технологии значений $\sim 900^{\circ} \mathrm{C}$.

Для роста нелегированных слоев $\mathrm{GaN}$ использовались подложки $\mathrm{Si}(111)$ и por- $\mathrm{Si}(111)$, прошедшие химическую подготовку с целью удаления органических загрязнений. Непосредственно перед ростом подложки отжигались в ростовой камере установки МПЭ ПА при температуре $T_{s}=850^{\circ} \mathrm{C}$ в течение 30 мин. После этого подложки $\mathrm{Si}(111)$ были нитридизованы при температуре $T_{s}=850^{\circ} \mathrm{C}$ в течение 30 мин в потоке активированного азота, соответствующем эквивалентной скорости роста $\mathrm{GaN}, F_{\mathrm{N}} \sim 0.1$ мкм/ч, с целью формирования переходного слоя нитрида кремния на поверхности $\mathrm{Si}(111)$.
Пористый слой кремния при создании „податливой“ подложки por-Si был сформирован на монокристаллической пластине $c-\mathrm{Si}(111)$ методом электрохимического травления в спиртовом растворе плавиковой кислоты по стандартной методике [6-8]. Толщина пористого слоя составляла $\sim 30$ нм. Задаваемый технологический средний размер пор составлял $\sim(1-5)$ нм.

Непосредственный синтез слоев $\mathrm{GaN}$ на нитридизованных подложках $\mathrm{Si}(111)$ состоял из двух стадий: сначала выращивался зародышевый слой LT-GaN толщиной 15 нм в низкотемпературном режиме, при $T_{s}=650^{\circ} \mathrm{C}$, и соотношении потоков галлия и активированного азота $1: 1$. После этого выращивался основной слой HT-GaN толщиной $\sim 820$ нм в высокотемпературном режиме, при $T_{s}=730^{\circ} \mathrm{C}$, и соотношении потоков элементов $\mathrm{V}$ и III группы $\mathrm{V} / \mathrm{III} \approx 6$.

Концентрации элементов в слоях были уточнены методом рентгеновского микроанализа с использованием приставки к электронному микроскопу.

Концентрация носителей и тип проводимости определялись с помощь эффекта Холла методом Ван дер Пау при комнатной температуре с использованием установки Ecopia-3000 (Корея). Планарные серебряные контакты толщиной 30 нм были нанесены на пленки методом магнетронного напыления.

Исследования фазового состава поверхности методом рентгеновской фотоэлектронной спектроскопии (XPS) были выполнены на лабораторном спектрометре фирмы SPECS, возбуждение $\mathrm{Mg} K_{\alpha}$.

Микроскопические исследования качества гетерограниц были выполнены на электронном микроскопе Libra 120 Carl Zeiss. Изучение морфологии поверхности проводили с использованием сканирующего зондового микроскопа Femtoscan-001 NT MDT в режиме атомно-силовой микроскопии.

Рентгенофазовый анализ полученных образцов проводили методом рентгеновской дифракции с использованием дифрактометра ДРОН 4-07 с кобальтовой трубкой, излучение $\mathrm{Co}_{\alpha}$ с длиной волны $1.790 \AA$.

Структурное качество образцов, определение параметров решеток твердых растворов (кривые качания), а также анализ ориентации полученных наноколон с использованием полюсных фигур проводили методом рентгеновской дифракции на дифрактометре Seifert 3003 HR с 4-кружным гониометром и монохроматизированным излучением меди с длиной волны $\mathrm{Cu} K_{\alpha 1}=1.5405 \AA$.

\section{3. Экспериментальные результаты}

\section{1. Дифрактометрические исследования}

На рис. 1 приведены обзорные дифрактограммы для исследованных образцов $\mathrm{GaN} / c-\mathrm{Si}$ и $\mathrm{GaN} /$ por-Si, полученные в стандартной геометрии Брегга-Брентано. На экспериментальных дифрактограммах самыми интенсивными линиями являются: отражение от плоскости (111) 


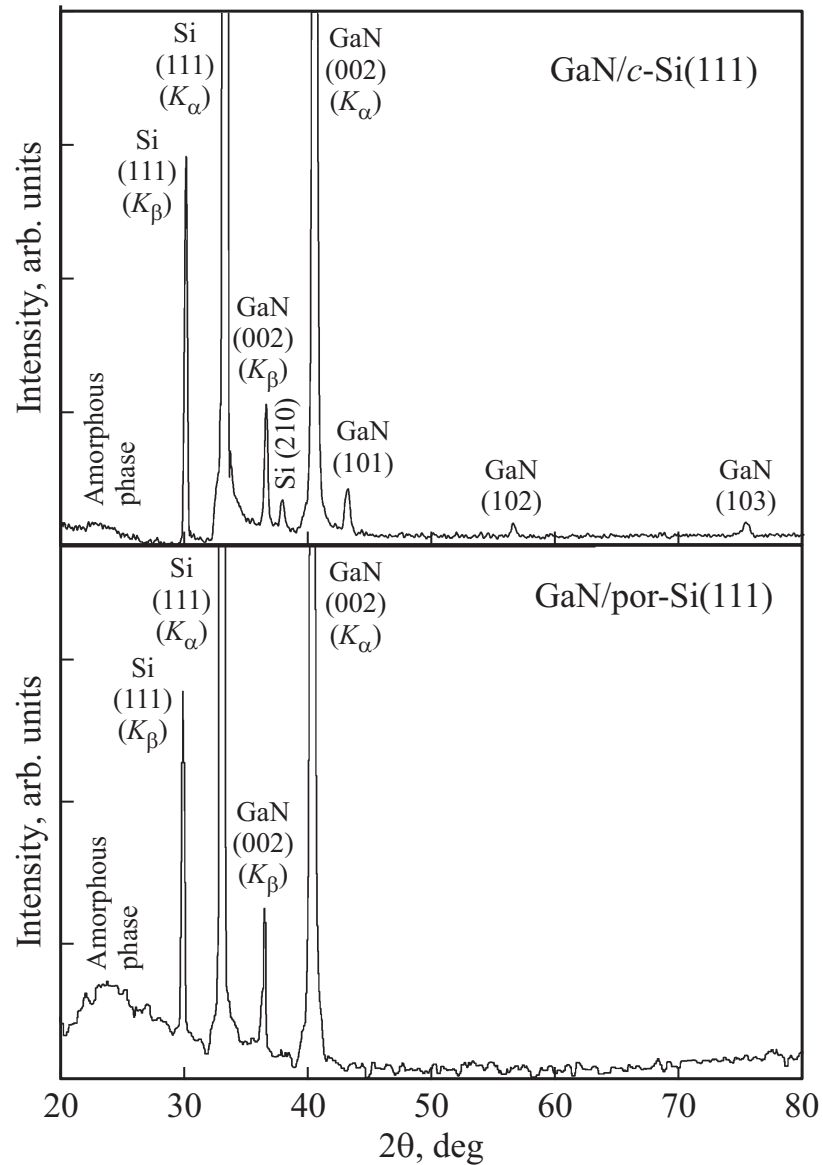

Рис. 1. Обзорная картина дифракции образцов гетероструктур $\mathrm{GaN} / c-\mathrm{Si}(111)$ и $\mathrm{GaN} /$ por-Si(111).

подложки Si и дифракционные рефлексы (0002), (0004) (нет на рис.) от слоя $\mathrm{GaN}$. Однако более детальное рассмотрение дифракционной картины позволяет сделать заключение о том, что для образца $\mathrm{GaN} / c-\mathrm{Si}$, выращенного на монокристаллической подложке, характерно присутствие слабых асимметричных отражений от эпитаксиального GaN. Появление этих дифракционных максимумов указывает на тот факт, что для пленки, полученной на монокристаллической подложке, характерна малая степень поликристалличности, так как коалесцировавшие при росте 2D слоя наноколонны $\mathrm{GaN}$ имеют разориентацию от направления роста. Что касается пленки, полученной на податливой подложке por-Si, на ее обзорной дифрактограмме дополнительные рефлексы отсутствуют и это означает, что пленка растет в монокристаллическом состоянии.

Хорошо известно, что параметры решетки в гетероструктуре, их несоответствие параметрам монокристаллической подложки и возникающие в этом случае напряжения могут быть определены из прямых измерений кривых качания.

На рис. 2 представлены экспериментальные кривые качания для исследованных образцов в геометрии $2 \theta-\omega$. На рис. 2, $a$ представлен рефлекс (111) $\mathrm{Si}$ от моно- кристаллической и „податливой“ подложек, а также разложение рефлекса для „податливой“ подложки на компоненты. На рис. $2, b$ приведен симметричный рефлекс (0002) для $\mathrm{GaN}$, а на рис. 2,c асимметричное отражение (1012) для $\mathrm{GaN}$.

Анализируя полученные данные дифракции (111) $\mathrm{Si}$ для подложек обоих типов, а также результаты разложения рефлекса (111) для „податливой“ подложки por-Si на компоненты, можно сделать следующие заключения. Хорошо видно, что профиль дифракционной линии (111) от монокристаллической подложки $c$-Si имеет асимметричную форму и большую полуширину, что, скорее всего, является следствием возникновения напряжений кристаллической решетки поверхностных слоев кремния из-за большой разницы параметров $\mathrm{Si}$ и $\mathrm{GaN}$. Рассчитанный параметр решетки $a_{c-\mathrm{Si}}=5.4254 \AA$.

В то же время можно заметить, что для гетероструктуры, выращенной на „податливой“ подложке por-Si, рефлекс (111) Si является суммой отражений от пористого слоя и $c$-Si и имеет меньшую полуширину, чем рефлекс от $c$-Si. Разложение дифракции на компоненты позволило рассчитать параметр решетки пористого слоя, $a_{\text {por-Si }}=5.4330 \AA$, и кристаллической подложки, $a_{c-\mathrm{Si}}=5.4232 \AA$. Хорошо видно, что параметр подложки $c$-Si хорошо согласуется с известными литературными значениями для $\mathrm{Si}$. Анализируя дифракцию от пористого слоя, форму дифракционного рефлекса и его полуширину, можно уверенно говорить, что пористый слой имеет более высокую степень кристалличности в сравнении с $c$-Si. При этом, в соответствии с данными работы [9], сформированный при создании „податливой“ подложки пористый слой содержит поры наноразмерного масштаба (единицы нанометров), что совпадает с нашими представлениями и соответствует режимам отработанной нами технологии создания пористых слоев в кремнии $[6,10]$.

С использованием уравнения Брегга

$$
2 d_{h k \overline{(k+l)}} \sin \theta=n \lambda
$$

и соотношения

$$
d_{000 l}=c / l,
$$

где $(h k l)$ - индексы Миллера для плосоксти дифракции, $d_{000 l}-$ межплоскостное расстояние для плоскости дифракции $(000 l), \theta-$ брэгговский угол дифракции, $a, c$ - параметры решетки $\mathrm{GaN}$ с вюрцитной структурой, на основе экспериментальных данных для симметричного рефлекса (0002) можем найти параметр решетки $c$ для пленки $\mathrm{GaN}$.

Далее, используя рассчитанное значение параметра $c$, а также данные асимметричного отражения (1012) и соотношение

$$
d_{h k(k+l)}=\frac{1}{\sqrt{\left(4 / 3 a^{2}\right)\left(h^{2}+k^{2}+h k\right)+l^{2} / c^{2}}},
$$

можем найти параметр $a$ для пленки $\mathrm{GaN}$. 


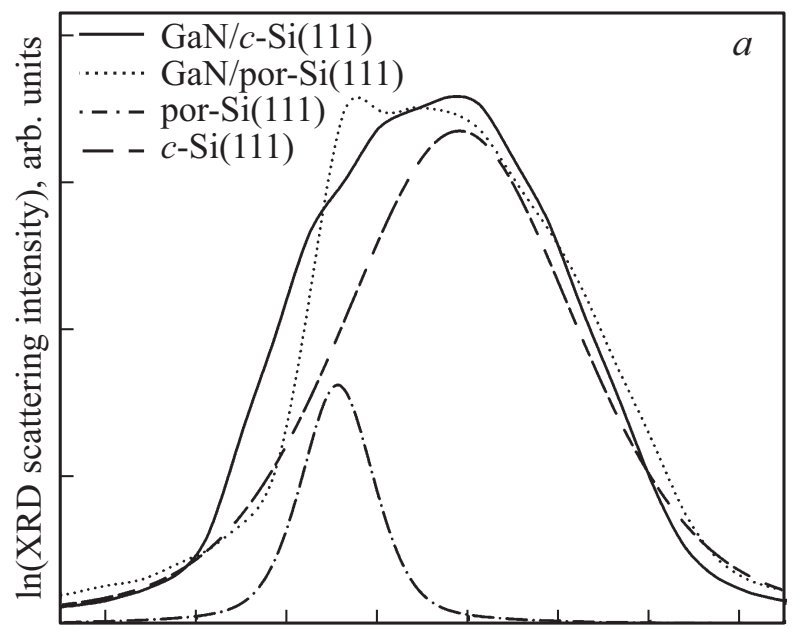

14.1614 .1814 .2014 .2214 .2414 .2614 .2814 .30 $\omega$, deg
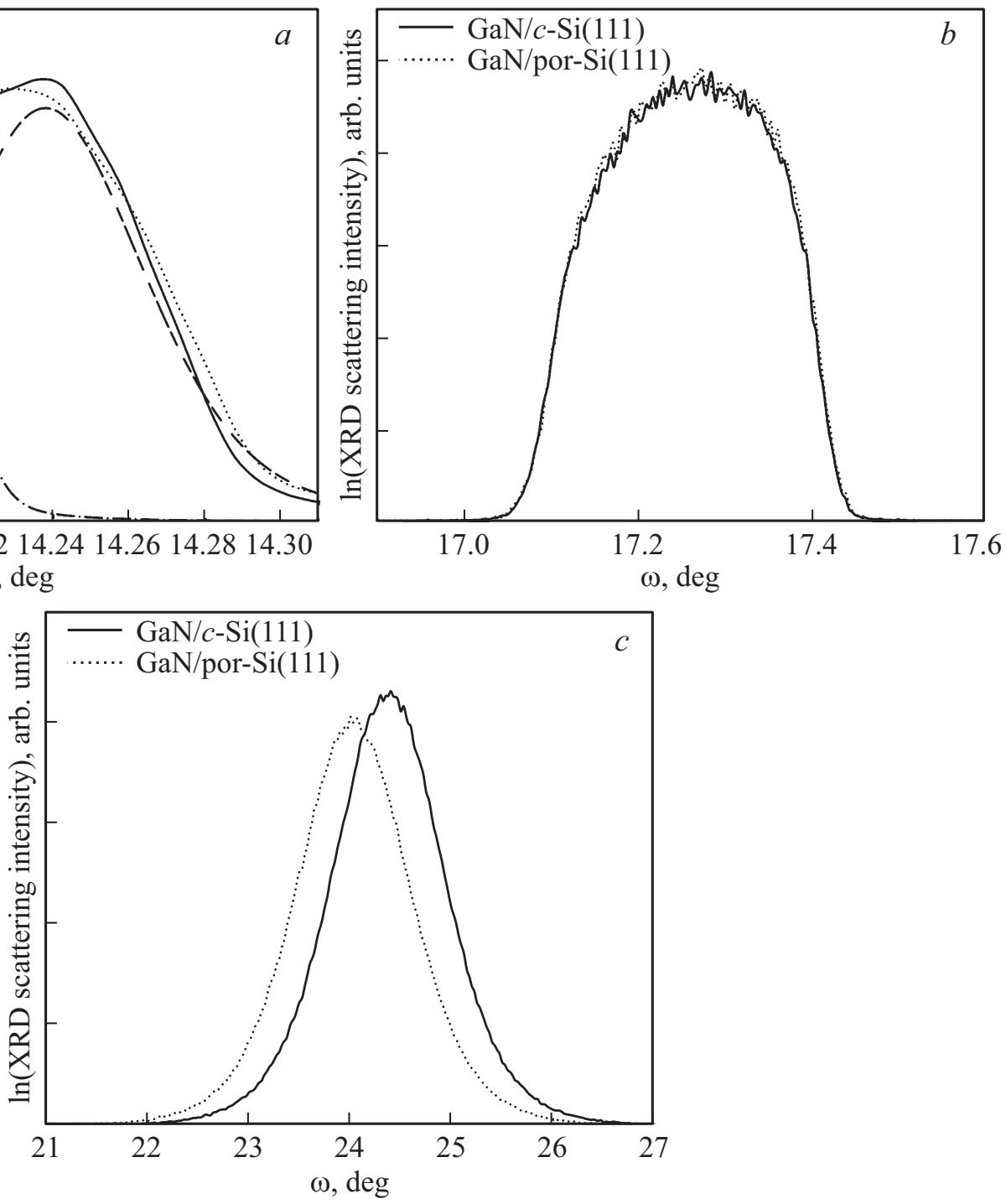

Рис. 2. Экспериментальные кривые качания для исследованных образцов в геометрии $2 \theta-\omega . a-$ скан рефлекса (111) $\mathrm{Si}$ для подложек $c$-Si и por-Si; $b$ - скан рефлекса (0002) $\mathrm{GaN}$; $b$ - скан рефлекса (1012) $\mathrm{GaN}$.

Рассчитанные параметры кристаллических решеток представлены в таблице.

Основываясь на теории упругости для напряженного слоя $\mathrm{GaN}$ с вюрцитной симметрией кристаллической решетки, компоненты деформации $\varepsilon_{x x}$ и $\varepsilon_{z z}$ (параллельный и перпендикулярный к поверхности эпитаксиального слоя) можно определить следующим образом [11-13]:

$$
\varepsilon_{x x}=\frac{a-a_{0}(x)}{a_{0}(x)}, \quad \varepsilon_{z z}=\frac{c-c_{0}(x)}{c_{0}(x)},
$$

где $a$ и $c$ - измеренные экспериментально параметры решетки $\mathrm{GaN}, a_{0}(x)$ и $c_{0}(x)$ - полностью релаксирован-

Результаты рентгеноструктурного анализа

\begin{tabular}{c|c|c|c|c|c|c|c}
\hline \multirow{2}{*}{ Образец } & \multicolumn{2}{|c|}{$\begin{array}{c}\text { Параметры } \\
\text { решетки }\end{array}$} & \multicolumn{2}{c|}{$\begin{array}{c}\text { Компоненты } \\
\text { деформации }\end{array}$} & \multicolumn{2}{|c|}{$\begin{array}{l}\text { Плотность } \\
\text { дислокаций }\end{array}$} & \multirow{2}{*}{ Дисторсия } \\
\cline { 2 - 7 } & $\begin{array}{c}c, \\
\AA\end{array}$ & $\begin{array}{c}a, \\
\AA\end{array}$ & $\varepsilon_{x x}$ & $\varepsilon_{z z}$ & $\begin{array}{c}\rho_{\text {screw }}, \\
\mathrm{cm}^{-2}\end{array}$ & $\begin{array}{c}\rho_{\text {edge }}, \\
\mathrm{cm}^{-2}\end{array}$ & \\
\hline $\mathrm{GaN} / \mathrm{c}-\mathrm{Si}(111)$ & 5.1933 & 3.1142 & -0.0235 & 0.0016 & $4.46 \cdot 10^{10}$ & $4.51 \cdot 10^{9}$ & -0.0681 \\
\hline $\mathrm{GaN} / \mathrm{por}-\mathrm{Si}(111)$ & 5.1952 & 3.1907 & 0.0005 & 0.002 & $4.39 \cdot 10^{10}$ & $4.3 \cdot 10^{9}$ & 4
\end{tabular}



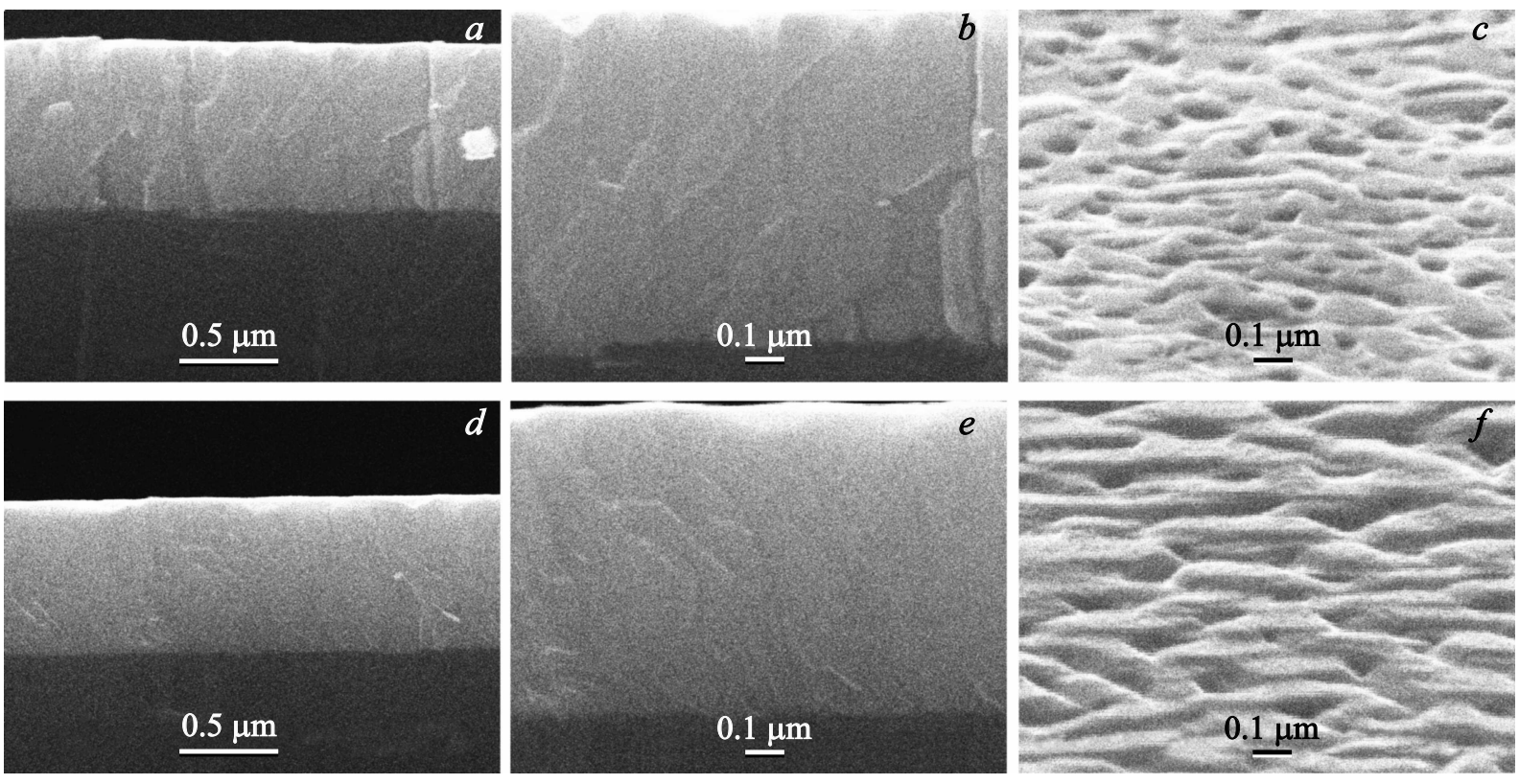

Рис. 3. Результаты исследований сколов $(a, b, d, e)$ и поверхности $(c, f)$ гетероструктур методом электронной микроскопии: $a, b, c$ - образец $\mathrm{GaN} / c-\mathrm{Si}(111) ; d, e, f$ - образец $\mathrm{GaN} /$ por-Si(111).

ные параметры решетки GaN. В расчете были использованы литературные значения для $\mathrm{GaN} c_{0}=5.1850 \AA$, $a_{0}=3.1892 \AA[14]$.

Хорошо известно, что деформация в плоскости роста $\varepsilon_{x x}$ связана линейно с деформацией в направлении роста $\varepsilon_{z z}$ через соотношение

$$
D=\frac{\varepsilon_{z z}}{\varepsilon_{x x}}
$$

$D$ - коэффициент дисторсии (искажения) кристаллической решетки слоя $\mathrm{GaN}$.

Рассчитанные с учетом (4), (5) значения компонент деформации $\varepsilon_{x x}$ и $\varepsilon_{z z}$, а также величина коэффициента дисторсии $D$, возникающей в пленке $\mathrm{GaN}$ с наноколончатой геометрией, представлены в таблице.

Следует отметить, что в соответствии с полученными результатами (см. таблицу) в случае использования „податливой“ подложки por-Si наблюдается когерентный эпитаксиальный рост. Кристаллическая ячейка эпитаксиального слоя $\mathrm{GaN}$ практически согласована по параметру решетки с пористым подслоем в плоскости роста, а в направлении роста ввиду пуассоновского эффекта элементарная ячейка испытывает значительную дисторсию $(D \approx 4)$. Рост слоя $\mathrm{GaN}$ на кристаллической подложке $c$-Si приводит к частичной релаксации решетки, как в плоскости, так и в направлении роста.

Как уже было отмечено выше, при синтезе нитрида галлия методом МПЭ ПА эпитаксиальный рост 2D пленки происходит за счет коалесценции наноколонн $\mathrm{GaN}$, которые могут быть разориентированы относительно заданного подложкой направления роста, что приводит к появлению большого числа дефектов в виде краевых и винтовых дислокаций. Эти дислокации проходят вдоль оси с кристаллической решетки, а их векторы Бюргерса характеризуют искажения, вызванные в кристаллической решетке дислокациями [15].

В соответствии со стандартной методикой [16] и соотношениями из $[17,18]$

$$
\begin{gathered}
\rho_{\text {dis }}=\rho_{\text {edge }}+\rho_{\text {screw }}, \\
\rho=\frac{\beta_{h k l}^{2}}{4.35 b^{2}}, \\
\left.b_{\text {screw }}^{2}=2.65 a^{2} \quad \text { (для винтовых дислокаций }\right), \\
\left.b_{\text {edge }}^{2}=1.3 a^{2} \quad \text { (для краевых дислокаций }\right),
\end{gathered}
$$

$\rho_{\text {dis }}-$ плотность дислокаций в пленке, $\rho_{\text {edge }}-$ плотность краевых дислокаций, $\rho_{\text {screw }}$ - плотность винтовых дислокаций, мы рассчитали плотность краевых дислокаций в слое $\mathrm{GaN}$, используя данные асимметричного скана и плотность винтовых дислокаций на основе данных симметричного отражения. Здесь $a$ - параметр решетки слоя GaN.

Рассчитанные плотности краевых и винтовых дислокаций представлены в таблице.

Сопоставление полученных нами результатов и уже известных литературных данных по величине плотности дислокаций в эпитаксиальном слое $\mathrm{GaN}$ c наноколончатой морфологией позволяет сделать вывод о том, что определенные экспериментально величины $\rho_{\text {edge }}$ и $\rho_{\text {screw }}$ лежат на границе значений, характерных для эпитаксиального сплошного слоя $\mathrm{GaN}$, для которого типичная плотность винтовых дислокаций, характеризующихся вектором Бюргерса $\langle 001\rangle$, имеет величину 

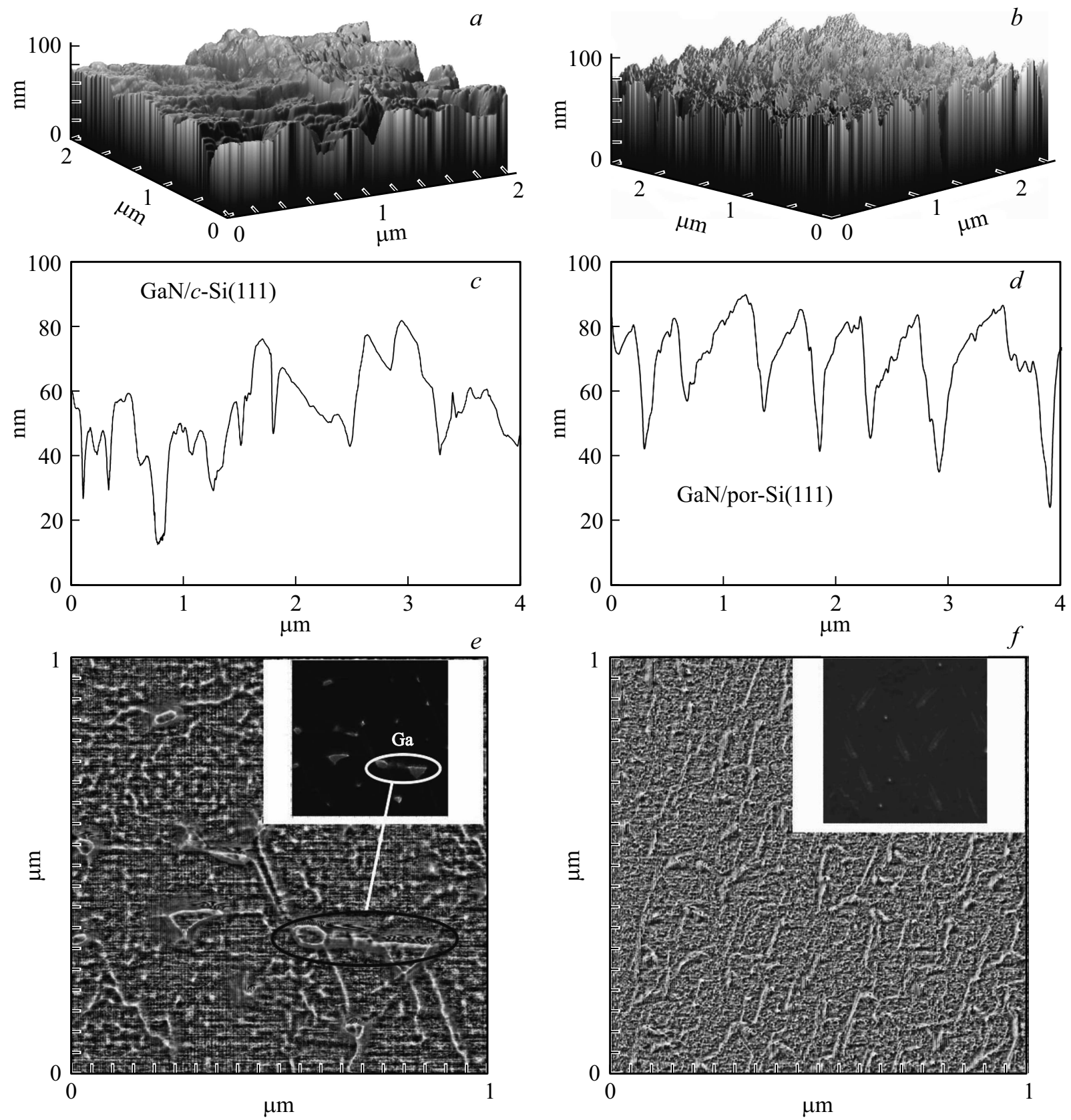

Рис. 4. Результаты ACM гетероструктур $\mathrm{GaN} / c-\mathrm{Si}(111)(a, c, e)$ и $\mathrm{GaN} /$ por-Si(111) $(b, d, f)$. $(a, b)$ - изображения характерного микроучастка поверхности гетероструктур; $(c, d)$ - функция распределения рельефа поверхности образцов; $(d, e)-$ фазовый контраст.

$10^{8}-10^{10} \mathrm{~cm}^{-2}$, а краевых (вектор Бюргерса $\left.1 / 3\langle 110\rangle\right)-$ величину порядка $10^{8}-10^{9} \mathrm{~cm}^{-2}$.

\section{2. Результаты сканирующей электронной и атомно-силовой микроскопии}

С использованием метода электронной микроскопии мы исследовали сколы гетероструктур $\mathrm{GaN} / \mathrm{Si}(111)$ и $\mathrm{GaN} /$ por-Si(111). Это позволило не только уточнить толщины слоев, но и охарактеризовать качество эпитаксиальной пленки, полученной на подложке из кристал- лического кремния $c-\mathrm{Si}(111)$ и „податливой“ подложке с пористым слоем por-Si(111).

Как видно из экспериментальных данных (см. рис. 3, $a$ и $d$ ), в едином технологическом процессе на подложке кристаллического кремния $c-\operatorname{Si}(111)$ и на податливой подложке por- $\mathrm{Si}(111)$ получен слой $\mathrm{GaN}$ толщиной $\sim(830-840)$ нм.

При этом детальное рассмотрение скола пленок $\mathrm{GaN}$ с большим увеличением $(\times 100000)$, представленное на рис. $3, b$ и $e$, показывает, что эпитаксиальный слой $\mathrm{GaN}$, полученный на податливой подложке por-Si(111), имеет 


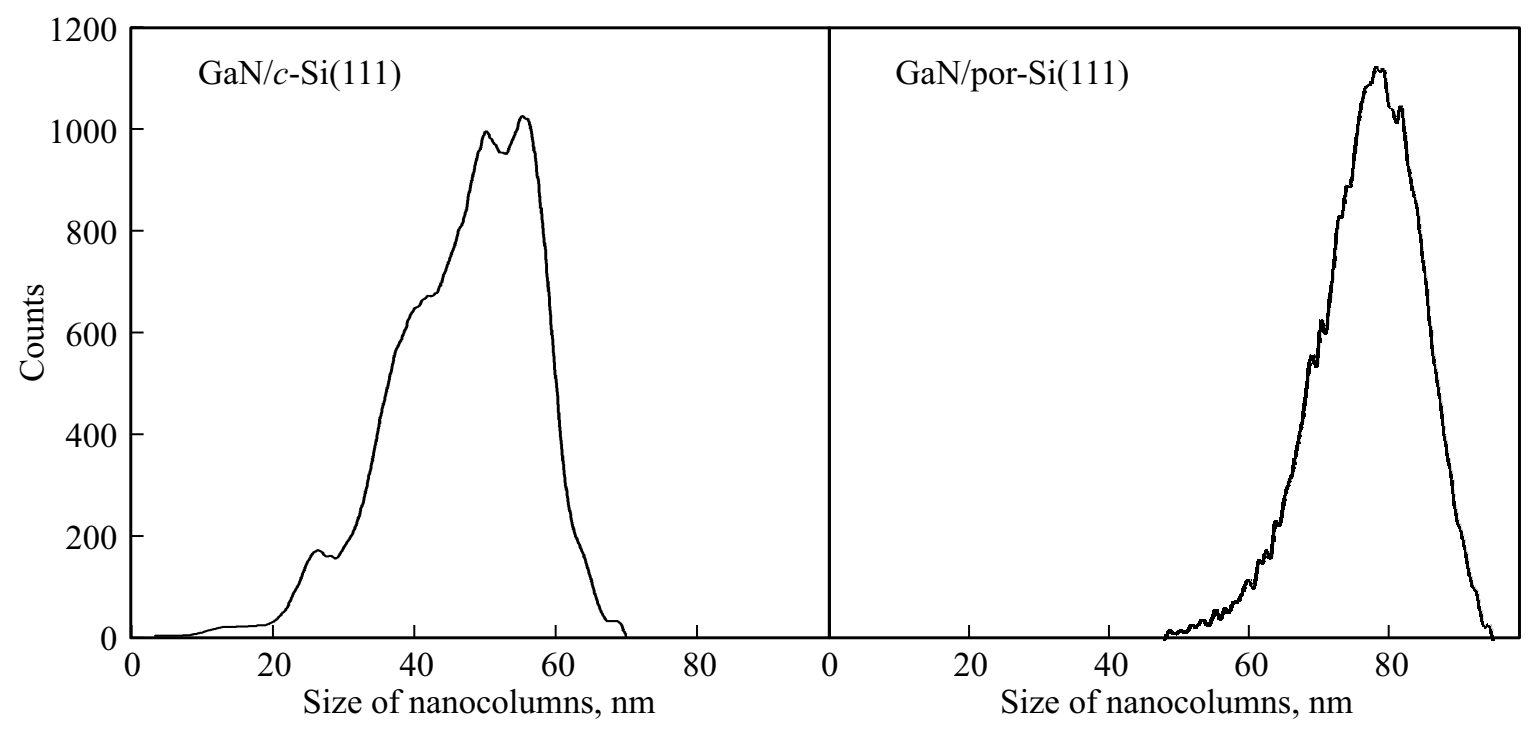

Рис. 5. Функция распределения размеров коалесцировавших наноколонн $\mathrm{GaN}$ на поверхности образцов $\mathrm{GaN} / c-\mathrm{Si}(111)$ и $\mathrm{GaN} /$ por-Si(111).

не только более качественный интерфейс $\mathrm{GaN}-\mathrm{Si}$, но и значительно меньшее число протяженных локальных дефектов, проходящих через толщу пленки, какими изобилует слой, выращенный на монокристаллической подложке $c-\mathrm{Si}(111)$.

Что же касается поверхности эпитаксиального слоя, то в случае роста $\mathrm{GaN}$ на податливой подложке (рис. $3, f$ ) она имеет ярковыраженный рельеф, обусловленный коалесценцией наноколонн $\mathrm{GaN}$.

Эти заключения согласуются с результатами исследования поверхности эпитаксиальных слоев $\mathrm{GaN}$ методом атомно-силовой микроскопии (см. рис. 4). На рис. 4 приведены изображение характерного микроучастка гетероструктур, функция распределения рельефа поверхности образцов, фазовый контраст.

Эксперимент показывает (см. рис. 4), что для поверхности гетероструктуры $\mathrm{GaN} / c-\mathrm{Si}(111)$ характерен больший перепад высот, образованный ростом и коалесценцией наноколонн, чем для структуры $\mathrm{GaN} /$ por-Si(111). При этом в случае роста на податливой подложке наноколонны $\mathrm{GaN}$ коалесцируют таким образом, что на поверхности образуется характерный упорядоченный микрорельеф (см. функцию распределения рельефа поверхности на рис. 4,d), чего не наблюдается для образца, выращенного на $c$-Si(111) (рис. 4,c). Кроме того, АСМ-анализ в режиме фазового контраста показал (см. рис. 4, $е$ и $f$ ), что на поверхности гетероструктуры $\mathrm{GaN} / \mathrm{Si}(111)$ присутствует фаза, отличная от $\mathrm{GaN}$, которая, вероятно, образовалась в процессе роста эпитаксиального слоя. Предположительно, эти наноразмерные объекты представляют собой агломераты металлического Ga.

Что касается диаметров коалесцировавших наноколонн $\mathrm{GaN}$, образовавших поверхностный рельеф (см. рис. 4 и 5), то обработка результатов АCМ по уже отработанной нами методике [19] показала, что в случае эпитаксиального роста на податливой подложке por-Si бо́льшая часть $(>80 \%)$ неоднородностей $\mathrm{GaN}$ имеет характерный размер $\sim(70-80)$ нм, в то время как для роста на монокристаллическом кремнии $c$-Si диаметр коалесцировавших наноколонн $\mathrm{GaN}$ широко варьируется, в пределах 20-70 нм.

\section{3. Полюсные фигуры}

Чтобы определить ориентацию слоя $\mathrm{GaN}$, полученного по нашей технологии выращивания наноколонн с последующей их коалесценцией в $2 \mathrm{D}$ слой, нами были получены полюсные фигуры для образца, выращенного на $c$-Si(111) и на „податливой“ подложке por-Si.

На рис. 6 приведены полюсные фигуры для отражения (111) от $\mathrm{Si},(0002)$ от $\mathrm{GaN}$ и (1012) от $\mathrm{GaN}$.

Из полученных экспериментальных данных хорошо видно, что на полюсных фигурах (111) от $\mathrm{Si}$ в центре полюсных фигур расположено интенсивное отражение от плоскости (111). Однако, если для образца, выращенного на подложке por-Si, никаких других рефлексов на полюсной фигуре не наблюдается, то на полюсной фигуре структуры, выращенной на $c$-Si, присутствуют два низкоинтенсивных отражения $\mathrm{Si}(111)$ и $\mathrm{Si}$ (111). Появление этих рефлексов на полюсной фигуре обусловлено, вероятно, разориентацией кристаллитов кремниевой подложки в области интерфейса. Электрохимическое травление исходной монокристаллической подложки $c$-Si при создании податливой подложки por-Si положительно сказывается на качестве переходной области (интерфейса), что находит свое отражение на полюсной фигуре (111) от $\mathrm{Si}$ для образца por-Si ввиду отсутствия на ней дополнительных рефлексов.

Что касается полюсных фигур (0002) от $\mathrm{GaN}$, как видно из эксперимента (см. рис. 6, $c$ и $d$ ), на картах обоих 

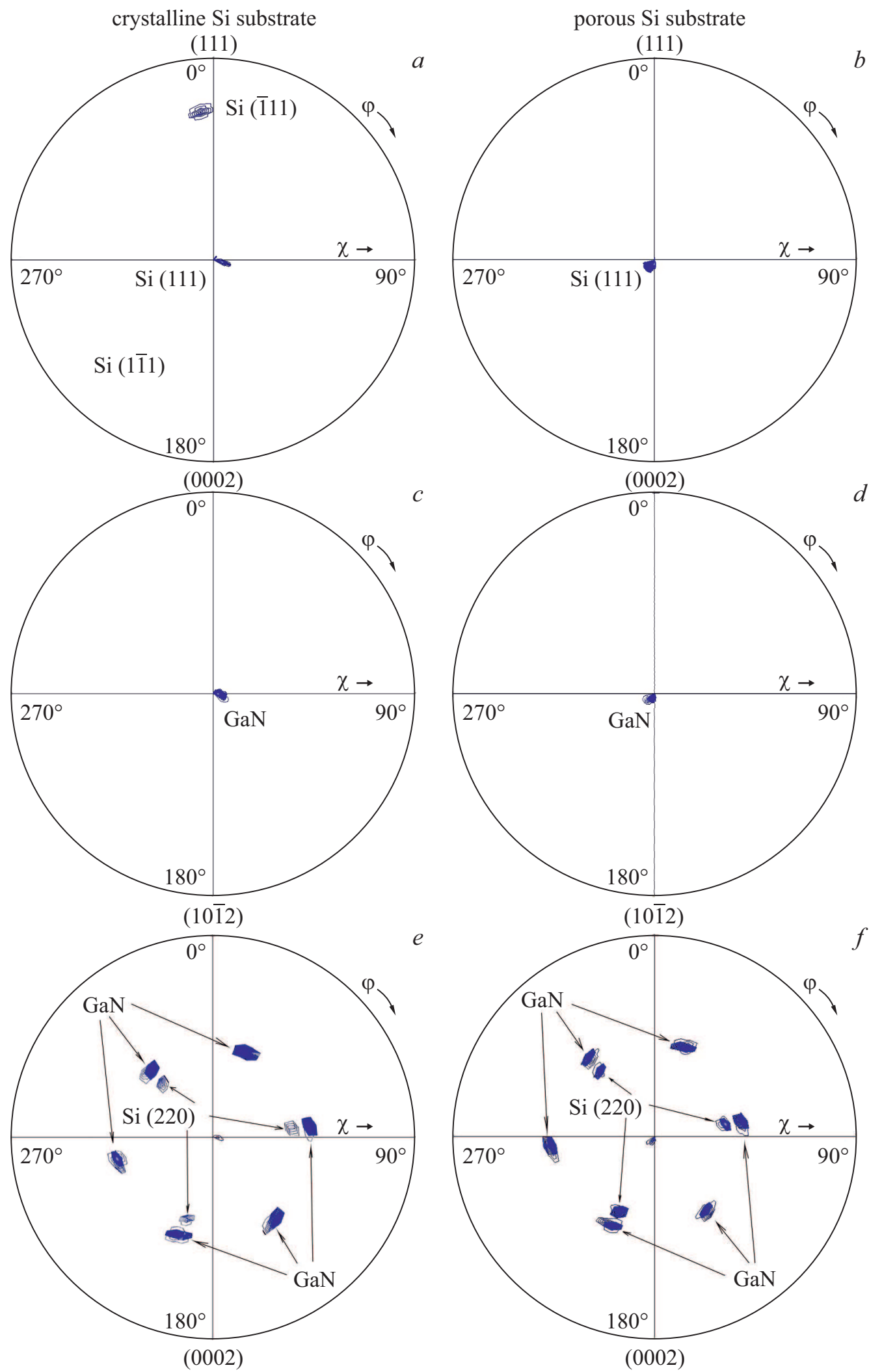

Рис. 6. Экспериментальные полюсные фигуры: $(a, b)$ - рефлекс (111) $\mathrm{Si} ;(c, d)$ - рефлекс $(0002) \mathrm{GaN} ;(e, f)-$ рефлекс $(10 \overline{1} 2)$ $\mathrm{GaN} .(a, c, d)$ - образец $\mathrm{GaN} / c-\mathrm{Si}(111) ;(d, e, f)$ - образец $\mathrm{GaN} /$ por-Si $(111)$. 
образцов рефлексы расположены в центрах полюсных фигур и никаких других отражений не наблюдается. Это означает, что ось с кристаллической решетки $\mathrm{GaN}$ перпендикулярна плоскостям $\mathrm{Si}(111)$.

Анализ экспериментальных данных на полюсных фигурах (1012) показывает (см. рис. 6, e и f), что для обоих образцов характерно присутствие трех внутренних рефлексов (при меньших $\chi$ ), соответствующих рефлексам от (220) плоскости $\mathrm{Si}$, а также шести внешних более интенсивных отражений от (1012) плоскости слоя $\mathrm{GaN}$, что свидетельствует об эпитаксиальном росте $\mathrm{GaN}$ с гексагональной сингонией, как на кристаллической подложке $c$-Si, так и на „податливой“ подложке por-Si.

Следует отметить, что присутствие на полюсной фигуре $(10 \overline{1} 2)$ не только отражений $\mathrm{GaN}$, но и рефлексов $\mathrm{Si}$ обусловлено близостью межплоскостных расстояний для этих фаз. Из распределения интенсивностей рентгеновского отражения на полюсной фигуре (1012) следует, что в реальном пространстве направления $\langle\overline{1} 10\rangle$ в кремнии параллельны направлениям $\langle 100\rangle$ в $\mathrm{GaN}$. Другими словами, для обоих образцов подложка $\mathrm{Si}$ задает ориентацию растущей наноколончатой структуры, которая впоследствии коалесцирует в $2 \mathrm{D}$ слой.

Также следует обратить внимание на тот факт, что на полюсной фигуре гетероструктуры, выращенной на por-Si (рис. 6, $e$ и $f$ ), интенсивность рефлексов (220) Si по отношению к интенсивности отражений от (1012) $\mathrm{GaN}$ выше, чем для структуры, выращенной на кристаллическом кремнии $c$ - $\mathrm{Si}$. Это позволяет сделать заключение о том, что в нашей технологии сформированные на первоначальной стадии роста наноколонны GaN имеют направление преимущественной ориентации роста ближе к направлению ориентации подложки гетероструктуры, полученной на податливой подложке por-Si.

Кроме того, анализ формы рефлексов (1012) GaN показывает, что на полюсной фигуре образца рефлексы эпитаксиального слоя имеют удлинение как вдоль направления $\varphi$, что объясняется большей разориентацией сформированных наноколонн в плоскости роста (малоугольным поворотом относительно друг друга), чем у образца, выращенного на „податливой“ подложке. Кроме того, на карте образца $\mathrm{GaN} / c-\mathrm{Si}$ рефлексы (1012) $\mathrm{GaN}$ имеют меньшее удлинение вдоль направления $\varphi$, чем для образца GaN/por-Si. Хорошо известно, что этот факт свидетельствует о большем наклоне наноколонн GaN по отношению к нормали к поверхности образца.

\section{4. Обсуждение полученных результатов}

С использованием метода молекулярно-пучковой эпитаксии с плазменной активацией азота на подложке $\mathrm{Si}(111)$ и por-Si(111) были выращены интегрированные гетероструктуры GaN/Si. На основе экспериментальных данных, полученных с использованием высокоразрешающей рентгеновской дифракции, сканирующей электронной и атомно-силовой микроскопии, мы можем сделать ряд заключений о механизмах эпитаксиального роста в методе МПЭ ПА и фундаментальных свойствах 2D слоя $\mathrm{GaN}$, полученного из зарождающегося массива наноколонн с их последующей коалесценцией в сплошной 2D слой на „податливой“ подложке por-Si, с предварительно сформированным слоем нанопористого кремния, а также провести сравнение этих данных с ростом на стандартной монокристаллической подложке $c$-Si.

На основании данных рентгеновской дифракции удалось показать, что полученный на подложках двух типов слой $\mathrm{GaN}$ имеет гексагональную симметрию кристаллической решетки. При этом подложки $c$-Si(111) и por-Si(111) задают ориентацию растущей наноколончатой структуры, которая впоследствии коалесцирует в 2D слой. Однако для слоя $\mathrm{GaN}$, полученного на монокристаллической подложке $c-\mathrm{Si}$, характерна малая степень поликристалличности эпитаксиальной пленки: при росте 2D слоя на $c$-Si коалесцировавшие наноколонны $\mathrm{GaN}$ имеют разориентацию относительно заданного подложкой направления роста, чего не наблюдается в случае роста на податливой подложке por-Si. При этом в соответствии с полученными результатами XRD в случае роста на „податливой“ подложке por-Si наблюдается практически когерентный эпитаксиальный рост слоя GaN. Кристаллическая ячейка эпитаксиального слоя $\mathrm{GaN}$ хорошо согласована по параметру решетки с пористым подслоем в плоскости роста, а в направлении роста ввиду пуассоновского эффекта элементарная ячейка испытывает значительную дисторсию $(D \approx 4)$. Рост слоя $\mathrm{GaN}$ на монокристаллической подложке $c$-Si приводит к росту эпитаксиального слоя GaN с частичной релаксацией кристаллической решетки как в плоскости, так и в направлении роста.

Кроме того, сформированные на первоначальном этапе синтеза наноколонны GaN в случае роста на стандартной подложке $c$-Si имеют бо́льшую разориентацию в плоскости роста (малоугловой поворот относительно друг друга) и больший наклон по отношению к нормали к поверхности образца, чем при росте на „податливой“ подложке. Кроме того, рост на податливой подложке por-Si позволил снизить плотности краевых и винтовых дислокаций по сравнению с величинами аналогичных коэффициентов для слоя, выращенного на $c$-Si.

Как уже было отмечено выше, на изображениях сколов образцов, полученных методом сканирующей электронной микроскопии (рис. 3), не наблюдается следов травления $\mathrm{Si}-\mathrm{Ga}$, которое связано с образованием эвтектики и следует из фазовой диаграммы $\mathrm{Ga}-\mathrm{Si}$ [16]. Долгий этап нитридизации поверхности подложек перед ростом позволил сформировать слой $\mathrm{Si}_{x} \mathrm{~N}_{y}$, выполняющий роль маски и предотвращающий прямой контакт металлического Ga с подложкой $\mathrm{Si}$ в процессе формирования зародышевого слоя $\mathrm{GaN}$ толщиной 10 нм образца на „податливой“ подложке por-Si.

Механические напряжения, возникающие из-за рассогласования коэффициентов температурного расширения $\mathrm{Si}$ и $\mathrm{GaN} \Delta \alpha_{\mathrm{Si}-\mathrm{GaN}}=2.9 \cdot 10^{-6} \mathrm{~K}^{-1}[20]$ могут быть 
рассчитаны как

$$
\sigma_{\mathrm{th}}=M_{\mathrm{GaN}} \int_{R T}^{T_{s}} \Delta \alpha_{\mathrm{Si}-\mathrm{GaN}} d T .
$$

Используя значения биаксиального модуля $\mathrm{GaN}$ $M_{\mathrm{GaN}}=478$ ГПа [21] и температуры роста $T_{s}=700^{\circ} \mathrm{C}$, напряжения растяжения, возникающие при охлаждении гетероструктуры от температуры роста до комнатной, получаем значение $\sigma_{\text {th }}=970$ МПа. Как показано в работе [22] для слоев с различными упругими свойствами, критическая толщина для распространения трещин параллельно интерфейсу может быть определена как

$$
h_{\text {critical }}=\Gamma \bar{E} / Z \sigma^{2},
$$

где $\Gamma-$ сопротивления материала трещинообразованию, $\bar{E}$ - плоскостной модуль упругости $\bar{E}=E /(1-v)$ (используется значение из [23] $\bar{E}=379$ ГПа для $\mathrm{GaN}$ ), $Z=g(\alpha, \beta) \cdot \pi / 2$.

Если предположить, что слой $\mathrm{GaN}$ формировался интегрально полностью релаксированным, то с учетом значений, приведенных в [22], и вычисленного нами значения $\sigma_{\mathrm{th}}=970 \mathrm{MПа} \mathrm{критическая} \mathrm{толщина} \mathrm{трещино-}$ образования составит $h_{\text {critical }} \approx 800$ нм. Согласно нашим экспериментальным данным, толщина полученного нами слоя на податливой подложке por- $\mathrm{Si}(111)$ составляет 825 нм, а на монокристаллической подложке $c$ - $\mathrm{Si}(111)$ $\sim 850$ нм. При этом данные оптической микроскопии подтверждают отсутствие трещин на поверхности гетероструктур. Мы считаем, что использование низкотемпературного буферного слоя с 3D морфологией поверхности приводит к снятию напряжений, генерируемых на интерфейсе $\mathrm{GaN}-\mathrm{Si}(111)$ на боковых свободных поверхностях наноколонн. Использование нанопористого слоя por-Si позволяет снизить плотность прорастающих дислокаций благодаря снижению степени угловой и плоскостной разориентации зародышевых островков, что соответственно снижает генерацию дислокаций несоответствия.

\section{5. Заключение}

С использованием метода молекулярно-пучковой эпитаксии с плазменной активацией азота были получены интегрированные гетероструктуры на основе самоупорядоченного массива наноколонн $\mathrm{GaN}-\mathrm{Ha}-\mathrm{Si}$ с достаточно однородным распределением диаметров, впоследствии коалесцировавших в 2D слой.

На основе данных структурных методов анализа было показано, что выращиание пленки GaN методом МПЭ ПА с использованием зародышевого 3D слоя $\mathrm{GaN}$ на „податливой“ кремниевой подложке с нанопористым буферным слоем por-Si(111) имеет ряд преимуществ по сравнению с ростом на подложке монокристаллического кремния $c$-Si.
Подложки обоих типов, $c-\operatorname{Si}(111)$ и por-Si(111), задают ориентацию растущей наноколончатой структуры, которая впоследствии коалесцирует в 2D слой. Однако рост наноколонн $\mathrm{GaN}$ на подложке por-Si происходит без разориентации относительно заданного подложкой направления роста, разориентации в плоскости роста и наклона по отношению к нормали к поверхности образца, в отличие от роста на $c-\mathrm{Si}$.

Кроме того, использование „податливой“ подложки por-Si обеспечивает практически когерентный эпитаксиальный рост слоя $\mathrm{GaN}$. Рост слоя $\mathrm{GaN}$ на монокристаллической подложке $c$-Si приводит к частичной релаксации кристаллической решетки слоя, как в плоскости, так и в направлении роста. Кроме того рост на податливой подложке por-Si позволил снизить плотности краевых и винтовых дислокаций по сравнению с величинами аналогичных коэффициентов для слоя, выращенного на $c$-Si.

Таким образом, использование „податливых“ $\mathrm{Si}$-подложек является применимым подходом для формирования полупроводниковых приборных гетероструктур на основе GaN методом МПЭ ПА.

\section{Благодарности}

We acknowledge the Karlsruhe Nano Micro Facility (KNMF, www.kit.edu/knmf) of the Forschungszentrum Karlsruhe for provision of access to instruments at their laboratories.

\section{Финансирование работы}

Работа выполнена при поддержке гранта президента РФ МД-42.2019.2 и при финансовой поддержке постановления № 211 Правительства Российской Федерации, контракт № 02.A03.21.0006.

Ростовые эксперименты проводились в рамках выполнения государственного задания министерства образования и науки Российской Федерации № 16.9789.2017/БЧ.

В части диагностики интегрированных структур работа поддержана грантом № 11.4718.2017/8.9 Министерство образования и науки России в рамках государственного задания вузам в сфере научной деятельности на 2017-2019 гг.

Работа в части исследований управления морфологией и составом монолитной и пористой подложек, выполнена при финансовой поддержке ФТИ им. А.Ф. Иоффе.

\section{Список литературы}

[1] I. Roland, M. Gromovyi, Y. Zeng, M. El Kurdi, S. Sauvage, C. Brimont, T. Guillet, B. Gayral, F. Semond, J.Y. Duboz, M. de Micheli, X. Checoury, P. Boucaud. Sci. Rep., 6, 34191 (2016).

[2] K. Nishi, K. Takemasa, M. Sugawara, Y. Arakawa. IEEE J. Select. Top. Quant. Electron., 23, 1 (2017).

[3] P.V. Seredin, D.L. Goloshchapov, A.S. Lenshin, A.M. Mizerov, D.S. Zolotukhin. Phys. E: Low-Dim. Syst. Nanostructures, 104, 101 (2018). 
[4] P.V. Seredin, A.S. Lenshin, D.S. Zolotukhin, I.N. Arsentyev, A.V. Zhabotinskiy, D.N. Nikolaev. Phys. E: Low-Dim. Syst. Nanostructures, 97, 218 (2018).

[5] P.V. Seredin, A.S. Lenshin, D.S. Zolotukhin, I.N. Arsentyev, D.N. Nikolaev, A.V. Zhabotinskiy. Phys. B: Condens. Matter, 530, 30 (2018).

[6] A.S. Lenshin, P.V. Seredin, B.L. Agapov, D.A. Minakov, V.M. Kashkarov. Mater. Sci. Semicond. Process, 30, 25 (2015).

[7] A.S. Len'shin, V.M. Kashkarov, P.V. Seredin, B.L. Agapov, D.A. Minakov, V.N. Tsipenyuk, E.P. Domashevskaya. Techn. Phys., 59, 224 (2014).

[8] V.M. Kashkarov, A.S. Len'shin, P.V. Seredin, B.L. Agapov, V.N. Tsipenuk. J. Surf. Investig. $X$-ray Synchrotron Neutron Techn., 6, 776 (2012).

[9] R.J. Martín-Palma, L. Pascual, P. Herrero, J.M. MartínezDuart. Appl. Phys. Lett., 81, 25 (2002).

[10] P.V. Seredin, A.S. Lenshin, D.L. Goloshchapov, A.N. Lukin, I.N. Arsentyev, A.D. Bondarev, I.S. Tarasov. Semiconductors, 49, 915 (2015).

[11] P.V. Seredin, A.V. Glotov, E.P. Domashevskaya, I.N. Arsentyev, D.A. Vinokurov, A.L. Stankevich, I.S. Tarasov. Semiconductors, 44, 1106 (2010).

[12] P.V. Seredin, A.V. Glotov, V.E. Ternovaya, E.P. Domashevskaya, I.N. Arsentyev, D.A. Vinokurov, A.L. Stankevich, I.S. Tarasov. Semiconductors, 45, 481 (2011).

[13] P.V. Seredin, V.E. Ternovaya, Glotov A.V., A.S. Len'shin, I.N. Arsent'ev, D.A. Vinokurov, I.S. Tarasov, H. Leiste, T. Prutskij. Phys. Solid State, 55, 2161 (2013).

[14] S. Adachi. Properties of semiconductor alloys: group IV, III-V and II-VI semiconductors, 1st edn (Wiley, Chichester, UK, 2009). http://doi.wiley.com/10.1002/9780470744383.

[15] I. Booker, L. Rahimzadeh Khoshroo, J.F. Woitok, V. Kaganer, C. Mauder, H. Behmenburg, J. Gruis, M. Heuken, H. Kalisch, R.H. Jansen. Phys. Status Solidi C, 7, 1787 (2010).

[16] R.W. Olesinski, N. Kanani, G.J. Abbaschian. Bull. Alloy Phase Diagr., 6, 362 (1985).

[17] T. Metzger, R. Höpler, E. Born, O. Ambacher, M. Stutzmann, R. Stömmer, M. Schuster, H. Göbel, S. Christiansen, M. Albrecht, H.P. Strunk. Philos. Mag. A, 77, 1013 (1998).

[18] S.K. Hong, T. Yao, B.J. Kim, S.Y. Yoon, T.I. Kim. Appl. Phys. Lett., 77, 82 (2000).

[19] E.P. Domashevskaya, P.V. Seredin, A.N. Lukin, L.A. Bityutskaya, M.V. Grechkina, I.N. Arsentyev, D.A. Vinokurov, I.S. Tarasov. Surf. Interface Anal., 38, 828 (2006).

[20] Y. Cordier, N. Baron, S. Chenot, P. Vennéguès, O. Tottereau, M. Leroux, F. Semond, J. Massies. J. Cryst. Growth., 311, 2002 (2009).

[21] A. Ubukata, K. Ikenaga, N. Akutsu, A. Yamaguchi, K. Matsumoto, T. Yamazaki, T. Egawa. J. Cryst. Growth, 298, 198 (2007).

[22] S. Raghavan, J.M. Redwing. J. Appl. Phys., 98, 023514 (2005).

[23] I. Vurgaftman, J.R. Meyer. J. Appl. Phys., 94, 3675 (2003).

Редактор Л.В. Шаронова

\section{Structural and morphological properties of GaN based hybrid heterostructures grown on compliant por-Si(111) substrate}

P.V. Seredin ${ }^{1,2}$, D.L. Goloshchapov ${ }^{1}$, D.S. Zolotukhin ${ }^{1}$, A.S. Lenshin ${ }^{1}$, A.M. Mizerov ${ }^{3}$, I.N. Arsentyev ${ }^{4}$, Harald Leiste $^{5}$, Monika Rinke ${ }^{5}$

${ }^{1}$ Voronezh State University, 394006 Voronezh, Russia

${ }^{2}$ Ural Federal University, 620002 Ekaterinburg, Russia

${ }^{3}$ St. Petersburg National research Academic University, Russian Academy of Sciences, 194021 St. Petersburg, Russia

${ }^{4}$ loffe Institute, 194021 St. Petersburg, Russia

${ }^{5}$ Karlsruhe Nano Micro Facility

H.-von-Helmholtz-Platz 1,

76344 Eggenstein-Leopoldshafen, Germany

Abstract In this paper, we demonstrate the possibility of GaN/por-Si(111) heterostructures fabrication by plasma-assisted molecular beam epitaxy on traditional $\mathrm{Si}(111)$ substrates without using AlN buffer layer. Positive influence of the high-temperature nitridation step on crystalline quality was confirmed. We showed that usage of compliant substrates, low growth temperature and $\mathrm{N}$-rich growth conditions help to achieve self-organized array of the $\mathrm{GaN}$ nucleation nanocolumns with homogeneous diameters distribution, which acts as buffer layer for further thick GaN layer formation at higher growth temperature and Ga-rich growth conditions. Higher growth temperature and Ga-rich conditions led to formation of the continuous GaN thick layer due to coalescence process of nuclear nanocolumns. Thus, usage of compliant por-Si substrates may be suitable for $\mathrm{GaN} / \mathrm{Si}(111)$ heterostructures with reasonable crystalline quality fabrication by plasma-assisted molecular beam epitaxy. 